\title{
Study on the Innovation of Piano Teaching in Normal Colleges and Universities
}

\author{
Lixia Li \\ Sichuan University of Arts and Science, Dazhou, China \\ Email: lilixia@163.com
}

How to cite this paper: Li, L. X. (2018) Study on the Innovation of Piano Teaching in Normal Colleges and Universities. Creative Education, 9, 697-701.

https://doi.org/10.4236/ce.2018.95051

Received: March 19, 2018

Accepted: April 20, 2018

Published: April 23, 2018

Copyright (C) 2018 by author and Scientific Research Publishing Inc. This work is licensed under the Creative Commons Attribution International License (CC BY 4.0).

http://creativecommons.org/licenses/by/4.0/

\begin{abstract}
At present, China's economic, political and cultural levels are developing at a relatively fast pace. The state attaches great importance to the development of higher schools education. In particular, the reforms of exam-oriented education mode make the development of music education in China stay in a very favorable environment. So, in this new historical phase, the piano teaching in colleges and universities in China should establish a new teaching system, improve the teaching system and teaching content which is not comprehensive, and explore and innovate new teaching methods in order to continuously improve the teaching level of piano lessons. This paper puts forward some innovative methods of piano teaching in higher normal colleges and universities by studying the common bad phenomena in piano teaching in colleges and universities.
\end{abstract}

\section{Keywords}

Colleges and Universities, Piano Teaching, Innovate

\section{Introduction}

Piano teaching is a compulsory course for pre-school education in higher normal colleges and universities. On one hand, the basic teaching of piano can provide basic guarantee for the smooth development of other courses; on the other hand, it can accumulate more teaching experience for students in higher normal colleges and universities. In the context of the current curriculum reform, traditional education has been unable to meet the teaching standards of cultivating students' innovative ability, emotional awareness and humanistic spirit (Zhao, 2014).

Students will learn how to play the piano according to the teacher's instructions and demonstrations. However, students' learning initiatives are not strong, 
and participation willingness is not enough. The students can play the piano, but usually can't express the ways in words, because their ideas are not clear. In other words, students usually imitate the teachers to play the piano rather than understanding how to play the piano really and understand the theories. As a result, these students will not be able to do the job if they enter the society as piano teachers, which will impede the popularization and development of piano business in China. Thus teachers of colleges and universities should try to make up for these shortcomings, break through the traditional teaching modes and make bold innovations in everyday teaching in order to cultivate more and more qualified piano teaching talents for the society.

\section{The Widespread Bad Phenomenon in Piano Teaching in Colleges and Universities}

\subsection{Lack of Correct Understanding of the Basic Knowledge of Piano}

The basic knowledge of piano is the first step for beginners to learn how to play the piano. However, due to the influence of the current bad education concept, many students who just begin to learn how to play the piano and even teachers, do not know enough about the importance of the basic knowledge of the piano. They think that the key to learning piano is to master some of the basic skills of piano playing, and the mastery of basic theory of piano is optional. This is actually quite incorrect. It's like building a building. If its foundation is not fixed, even if the superstructure is well built, the lower layer cannot bear its weight. And eventually, there will be all kinds of drawbacks and shortcomings. However, the firm grasp of the basic theory of piano can make the students more and more comfortable in the future piano performances. At the same time, students who have just entered the university rarely touch the piano before entering the college or university, letting alone a deeper understanding of the basic theory of piano. Therefore, it is necessary to teach students the basic knowledge of piano (Liu, 2013).

\subsection{The Piano Teaching Etudes Are Single and Fixed}

The instruction of fingering practice of piano teaching is a very important and difficult learning content. After a period of fingering practice of piano, the performance of students' fingers is directly related to the further study stages of piano. However, due to the limited exposure of students to professional piano training before entering the colleges and universities. Therefore, in the learning process of piano fingering practice, there are some kinds of unreasonable phenomena which are inevitable. In the current colleges and universities piano teaching, teachers often select piano etudes are more traditional and conservative in the process of piano teaching.

Many students are influenced by various factors in the learning process of the piano, and gradually reduce or even lose interest in piano. Though students have 
a high enthusiasm for piano learning at the beginning, however, if the piano teaching etudes are single and fixed, students will gradually reduce or even lose interest in learning piano. After a long and vicious cycle, the students' mastery of piano playing skills are even worse. So, in actual piano teaching, teachers should make appropriate and reasonable expansion of existing teaching methods, and should also enrich the teaching contents in order to improve students' enthusiasm, and improve their mastery of piano playing skills at last.

\subsection{Lack of Piano Teaching Effectiveness}

As to the piano performance learning, it is usually necessary to coordinate the four parts of the fingers, wrist, arm and body to achieve the perfect piano performance. And because of this, the teachers will also let the students carry on the practice of repeated mechanization in the piano teaching process in order to enable students to master skillfully and deeply. But because of this mechanical repetition practice, the students often lack a purpose and planning, so students not only waste a lot of time in studying piano playing, but also suffer from such bad phenomena as emotional boredom and numbness. This kind of aimless, unplanned piano teaching is difficult to achieve certain validity. Therefore, in order to avoid the occurrence of this undesirable phenomenon, when teaching piano lessons to students, teachers should avoid repeated mechanical exercises with no plans or goals. Instead, teachers should focus on the effectiveness of piano teaching and cultivate students' confidence in piano learning (Wang, 2017).

Therefore, students should have some particular purpose or target when they practicing playing the piano repeatedly. Teachers should help students to keep their interests in playing the piano.

\section{Reform and Innovation Ways of Piano Teaching in Colleges and Universities}

\subsection{Set up the Correct Goal of Piano Teaching}

In order to make piano teaching healthy and effective, teachers should let students have a comprehensive and systematic understanding of the basic theoretical knowledge, playing skills and related development history of the piano when teaching piano lessons to students. Teachers in colleges and universities should decompose and teach classic music works of different types in different periods, and enable students to master basic playing methods and skills through repeated practice with clear aims. They also should expand the student's playing techniques continuously and help the student to master the basic performance methods better with the aim of improving the students' performance skills. In addition, teachers should take students' understanding and performance of music as the main teaching objective. Teachers should not only train students to have some certain emotional cognitions, but also cultivate students' correct outlooks on life and values in the process of piano teaching. By this way, teachers let students learn to discover the beauty of life through the feeling and experience of 
music, and establish a healthy and correct aesthetic standards. Apart from that, teachers should also pay attention to the addition of Chinese elements in piano teaching. In the course of learning piano lessons, students will enhance their confidence and pride in learning the piano (Wang, 2014).

\subsection{Group Cooperative Teaching Method}

Group cooperative teaching is a very effective new teaching method, which can fully display the students' main status. The teachers should gradually transform from the leader of the traditional classroom to the guider. Students are able to choose their learning priorities according to their own preferences and learning abilities and put forward some reasonable research questions on basis of the current teaching situation. Teachers could teach students some basic teaching skills and musical knowledge before the course begins and then divide the students into multiple learning groups to collaborate and exchange with each other. In the process of group cooperation, students can ask the teacher for help in the first time if they have problems. Students could give their opinions and advice in an equal manner with teachers.

In the course of piano teaching, teachers should add some group courses appropriately to enable the students to enhance their mutual understandings in the collective atmosphere. At the same time, the teacher should set some discussion questions as much as possible, and participate in it together with students. To teach students some difficult points and key points, teachers could divide the students into different groups to discuss and exchange opinions, then let the students find out the answer in the way of enlightening them. This can not only establish students' confidence in piano learning, but also stimulate students' strong learning interest.

\subsection{Teach Students According to Their Aptitude and Learning Abilities}

In the actual education process, some normal colleges or university students has not learned the basics of piano learning at all. Even students who have been exposed to a piano for a period of time are far below the level of teaching. Therefore, teachers should fully understand each student's piano level and interests, comprehensively master individual differences among professional students in order to lay a good foundation for future teaching. Second, teachers should also eliminate the full-class and cramming teaching methods. On the one hand, it is necessary to help students to overcome their fears for piano lessons. On the other hand, it is necessary to guide students' performance skills so that their performance levels can be improved substantially on the existing basis. At last, teachers should adjust and improve the teaching contents according to their actual situation and personal preference (Yu, 2014).

And here's a thing to notice that teachers should try to select some outstanding songs to teach piano skills, and let the students have more experience in teaching. In the long run, the piano teaching difficulty will be in a low state. In 
turn, students' enthusiasm for learning can be sustained for a long time.

Teachers could also broaden students' music vision and improve students' aesthetic ability. In addition to teaching students the basic knowledge, such as the understanding of musical notation and other guidance, teachers should also cultivate students' ability to analyze the composer's creative intentions and styles. This method can cultivate students' aesthetic ability and expand their music visions, which provide certain prerequisites for its individualized developments. As to the piano teaching, the basic skill of piano playing is the main content of teaching, and a skilled piano player can enter the heart of the piano.

\section{Conclusion}

Piano teaching is a compulsory course for pre-school education in higher normal colleges and universities. It can help to provide basic guarantee for the smooth development of other courses, and also can accumulate more teaching experience for students in higher normal colleges and universities. So, it is an important course in normal colleges and universities. Colleges and universities should try to innovate the course teaching methods. This paper describes the present situation of piano teaching in colleges and universities at first, then analyzes some widespread bad phenomenon in piano teaching in colleges and universities, such as lack of correct understanding of the basic knowledge of piano, single and fixed piano teaching etudes, and lack of piano teaching effectiveness, and finally puts forward some reform and innovation ways of piano teaching in colleges and universities. However, teachers in colleges and universities should find out more innovative ways to promote the piano teaching.

\section{References}

Liu, H. Y. (2013). Discussion on the Innovative Strategy of Professional Piano Teaching in Normal Colleges and Universities. Journal of Taiyuan City Vocational and Technical College, 1 .

Wang, R. (2017). Study on the Present Situation of Professional Piano Teaching in Preschool Education in Normal University. Yellow River of the Song, 19.

Wang, Y. X. (2014). Discussion on the Role of Music Education in Moral Education. Popular Literature, 11.

Yu, J. (2014). Study on the Development of Dancing Education in Normal University. New West (Theoretical), 20.

Zhao, T. Y. (2014). Analysis on the Innovative Strategy of Education Professional Piano Teaching in Normal University. Music Space Time, 18. 